\title{
Studying Literature as Language
}

\author{
Roger Fowler \\ University of East Anglia
}

For the past twenty-five years or so, there has been a running dispute between literary critics and linguists on the question of whether it is appropriate to apply linguistic methods -that is to say, methods derived from the discipline of linguistics- to the study of literature. There has been almost universal confidence among the linguistis that this activity is entirely justified; and almost universal resistance by the critics, who have regarded the exercise with almost moral indignation. In this unyielding dispute, the claims and denials on both sides have been voiced with great force and passion. Here is Roman Jakobson putting the linguist's case, in 1958:

Poetics deals with problems of verbal structure, just as the analysis of painting is concerned with pictorical structure. Since linguistics is the global science of verbal structure, poetics may be regarded as an integral part of linguistics[1].

But the critics will not have this. In a long, bitter controversy between the late $F$. $\mathrm{W}$. Bateson and myself in 1967, the counterargument against linguistics was based essentially on an allegation of unfitness. Linguistics is a science, claims Bateson, but literature has what he calls an 'ineradicable subjective core' which is inaccessible to science. Again, linguistic processing is only a preliminary to literary response, so the linguist is incapable of taking us far enough in an account of literary form and experience. Finally, here is a dismissive opposition formulated by David Lodge, which is really saying that never the twain shall meet:

\footnotetext{
One still feels obliged to assert that the discipline of linguistics will never replace literary criticism, or radically change the bases of its claims to be a useful and meaningful form of human inquiry. It is the essential characteristic of modern linguistics that it claims to be a science. It is the essential characteristic of literature that it concerns values. And values are not anienable to scientific method[2].
}

The opposition between science and values is at the heart of the refusal to agree; it manifests itself in different specific forms in many distinct arguments among protagonists for the two cases. What I would like you to note in this contribution by Lodge is the way in which the key terms, 'science' and 'values,' are felt to be self-explanatory and conclusive. Lodge, like most of the debaters on both sides, 
requires us to take the central terms on trust, to accept them in their commonsense meanings with their ordinary values presupposed. In effect, Lodge is perceiving the two disciplines in terms of sterotypes, rather than analysing carefully the terms and concepts involved in the comparison. I do not say that Lodge is especially culpable, merely that this statement of his is characteristic of this habit, in the debate, of relying on undefined and sterotypical terms. Both sides are guilty of this.

I realised a long time ago that I must stop adding fuel to this dispute; since the confrontation was conducted in conditions of quite inadequate theorization, it was impossible to participate in it as a reasoned debate. Without getting envolved in the controversy again, I would like to merely mention some common failures of theorization which render it impossible to deal sensibly with a question so naively formulated as 'can linguistics be applied to literature?'

1. A major difficulty, on both sides, is a completely uncritical understanding of what is meant by 'linguistics.' 'The literary critics make no allowance for the fact that there exist different linguistic theories with quite distinct characteristics. While it might be true of linguistic model ' $A$ ' that it can or cannot carry out some particular function of criticism, the same might not be true of model 'B' which has a different scope or a different manner of proceeding. If the critics are not well enough informed to discriminate between models, the linguists do not acknowledge the distinctions; a linguist will work on literature in terms of the theory s/he happens to uphold as the 'correct' theory. Such is the competitiveness of the schools of linguistics that a devotee of one theory will not acknowledge that a rival might have some advantages for the task in hand.

2. A second persistent fallacy about linguistics, again represented on both sides, concerns the analytic modus operandi of linguistic method. It will be clear from what I have just said that different models have quite diverse aims, and procedures towards those aims. One model may have the purpose of accounting for the structure of particular texts; another may focus on sociolinguistic variation; another may be concerned to increase our knowledge about linguistic universals; and so on.

But there is a common misconception that linguistics -any linguistics- is a kind of automatic analyzing device which, fed a text, will output a description without human intervention. (The critics of course regard this as a soullessly destructive process, a cruelty to poems, but that is simply an emotional over-reaction based on a misconception). Now whatever differences there are between contemporary linguistic theories, I think they would all agree with Chomsky's insistence that linguistics is not a discovery procedure. Linguistic analysis works only in relation to what speakers know already, or what linguists hypothesize in advance. So the whole range of objections to linguistics on the grounds that it is merely a mechanical procedure can be dismissed; linguistic analysis is a flexible, directed operation completly under the control of its users, who can direct it towards any goals which are within the scope of the model being used. Complete human control is possible if you carefully theorize the nature of your objetive, and the nature of the object you are studying. 
Which leads to mention a second set of deficiencies in the way linguistic criticism is theorized, and then to the more positive part of my argument.

Even if critics and linguists positively acknowledge that language is of fundamental importance to the structure of the literary text, there is no guarantee that they will present language in a realistic and illuminating way. There are three representations of language that I regard as particularly unhelpful, and I will briefly instance them by reference to the work of scholars whose commitment to language is undoubted and substantial.

1. The first problematic attitude is that which regards language in literature as an object. This position is implicit throughout the work of Roman Jakobson[3]. Jakobson's 'poetic function' claims that the important thing about literature is the way in which structure is organised to foreground the substantive elements of the text-in particular, phonology and syntax. The patterns of parallelism and equivalents which he finds in his poems, at these levels of language, bulk out the formal structure, e. g. metrical and stanzaic structure, so that the text is represented as if its main mode of existence were perceptible physical form. The cost of this imaginary process is minimization of what we might call communicative and interpersonal -in a word, pragmatic-functions of the text. As I shall show in a moment, it is exactly these pragmatic dimensions which give the richest significance for critical studies. It is a pity that this 'objective' theory of language in literature should have been given currency by such a brilliant and influential linguist as Jakobson.

2. A second unhelpful attitude to language is that which treats it as a medium through which literature is transmitted. Here I quote David Lodge again: 'The novelist's medium is language: whatever he does, qua novelist, he does in and through language'[4]. Presumably language as a medium is analogous to paint, bronze or celluloid for other arts. But the metaphor easily comes to mean 'only a medium': the real thing is the novel (or poem, etc.) which is conveyed 'in and through' the medium. Thus the substance of literature is shifted into some obscure and defined, sphere of existence which is somehow beyond language. But for linguistics, literature is language, to be theorized just like any other discourse; it makes no sense to degrade the language to a mere medium, since the meanings, themes, larger structures of a text, 'literary' or not, are uniquely constructed by the text in its interrelation with social and other contexts. This position is difficult for literary critics to swallow, because it appears to remove the claimed special status (and value) of literature, to reduce it to the level of the language of the marketplace. But this levelling is essential to linguistic criticism if the whole range of insights about language provided by linguistics is to be made available. We want to show that a novel or a poem is a complexly structured text; that its structural form, by social semiotic processes, constitutes a representation of a world, characterized by activities and states and values; that this text is a communicative interaction between its producer and its consumers, within relevant social and institutional contexts. Now these characteristics of the novel or poem are no more that what functional linguistics is looking for in studying, say, conversations or letters or official documents. Perhaps this is a richer and thus more acceptable characterization of the aims of linguistic analysis than literary critics usually expect. But for me at any rate, 
this is what theorization as language involves. No abstract literary properties 'beyond' the medium need to be postulated, for the rhetorical and semiotic properties in question should appear within an ordinary linguistic characterization, unless linguistics is conceived in too restricted a way.

3. Implicit in what 1 have just said is my reluctance to accept one further assumption about language which is widespread in stylistics and criticism. This is the belief that there is a distinct difference between poetic or literary language on the one hand and ordinary language on the other. Critics generally take for granted some version of this distinction; and some linguists have attempted to demonstrate it: we find strong arguments to this effect in the writings of, for example, Jakobson and Mukarovsky. But these arguments are not empirically legitimate, and they are a serious obstacle to a linguistic criticism which attempts to allow to literature the communicative fullness that is a common property of all language.

I have given some reasons why the apparently simple question 'Can linguistics be applied to literature?' is unlikely to be satisfactorily answered. Because I believe that linguistics can very appropriately and revealingly be applied to literature, I want to re-orient the issue, in different terms. The solution is, it seems to me, to simply theorize literature as language, and to do this using the richest and most suitable linguistic model.

To be adequate to this task, a linguistic model should possess the following broad characteristics. It should be comprehensive in accounting for the whole range of dimensions of linguistic structure, particularly pragmatic dimensions. It should be capable of providing an account of the functions of given linguistic constructions (in real texts), particularly the thought-shaping (Halliday's 'ideational') function. It should acknowledge the social basis of the formation of meanings (Halliday's ‘social semiotic')[5].

The requisite linguisties for our purpose unlike most other, artificially restricted, forms of linguistics, should aim to be comprehensive in offering a complete account of language structure and usage at all levels: semantics, the organization of meanings within a language; syntax, the processes and orderings which arrange signs into the sentences of a language; phonology and phonetics, respectively the classification and ordering, and the actual articulation, of the sounds of speech; text-grammar, the sequencing of sentences in coherent extended discourse; and pragmatics, the conventional relationships between linguistic constructions and the users and uses of language.

Pragmatics is a part of linguistics which is still very much subject to debate and development|6|, but it is clear that it includes roughly the following topics: the interpersonal and social acts that speakers perform by speaking and writing; thus, the structure of not only conversation but also of all other sorts of linguistic communication as interaction; the diverse relationships between language use and its different types of context; particularly the relationships with social contexts and the historical development; fundamentally, the systems of shared knowledge within communities; and between speakers which make communication possible -this is where pragmatics and semantics overlap. In various 
writings I have stressed the need in linguistic criticism to mend the neglect of the interactional facets of 'literary' texts: the rhetorical relationships between addressor and addressee, the dynamics of construction of fictional characters, and the sociolinguistic relationships between the producers and consumers of literature[7]. The second strand of pragmatics, concerning linguistic structure and systems of knowledge, will enrich linguistic criticism even more, and bring it into positive collaboration with literary criticism.

A 'functional' model of language works an the premise that linguistic structures are not arbitrary, nor, as Chomsky claims, broadly constrained by universal properties of Mind. Rather, particular language structures assumed the forms they do in response to the communicative uses to which they are put, within a speech community. Halliday proposes three categories of 'function': ideational, interpersonal, and textual. The ideational function is a key concept in linguistic criticism. The experience of individuals, and, around them, their communities, is encoded in the language they use as sets of ideas; and the ideational will differ as the dominant ideas of speakers differ. A simple example would be the operational concepts of a science, coded for the relevant speakers in a technical terminology; for these speakers, the terminology is one part of the linguistic organization of their experience: though this is a specialized part of the ideational, a technical terminology is only an obvious instance of a general principle, namely that language structure, in its ideational function, is constitutive of a speaker's experience of reality.

And of a community's experience; this is what 'social semiotic' means. Although, undoubtedly, some of the meanings encoded in language are natural in origin, reflecting the kind of organism we are (e. g. basic colour, shape and direction terms)|8|, most meanings are social: the dominant preoccupations, theories or ideologies of a community are coded in its language, so that the semantic structure is a map of the community's knowledge and its organization. An important development of this principle follows from the fact that communities are ideologieally diverse: the existence of complex and competing sets of ideas gives rise to diverse style, registers or varieties carrying semiotically distinct versions of reality according to the distinct views of individuals and of sub-communities. For the critics, this is linguistic support for the traditional assumption (formulated by Leo Spitzer but implicit much more widely) that a style embodies a view of the world. The advance in Halliday's and my formulation is that the availability of a formal method of linguistic analysis facilitates the unpicking of relationships between style and the representation of experience.

I want now to look at a textual example; for economy of exposition, a very familiar passage. This will not 'prove the theory,' but it will suggest the directions in which this theory of language might take us. The extract is the opening of William Faulkner's The Sound and the Fury, a familiar but striking example of the way in which language structure gives form to a view of the world:

Through the fence, between the curling flower spaces, I could see them hitting. They were coming towards where the flag was and I went along the fence. Luster was hunting in the grass 
by the flower tree. They look the flag out, and they were hitting. 'Then they put the flag back and they went to the table, and he hit and the other hit. Then they went on, and they went along the fence. Luster came away from the flower tree and we went along the fence and they stopped and we stopped and I looked through the fence white Luster was hunting in the grass.

'Itere, caddie.' Ie hit. They went across the pasture. I held to the fence and watched them going away.

Listen at you, now,' l.uster said. 'Ain't you something, thirty-three years old, going on that way. After I done went, all the way to town to buy you that cake. Ilush up that moaning. Ain't you going to help me find that quarter so I can go to the show tonight?'

They were hitting little, across the pasture. I went back along the fence to where the flag was. It flapped on the bright grass and trees.

The character from whose point of view this part of the narrative is told is Benjy, a 33-year-old man with the mind of a young child. It is obvious that Faulkner has designed this language to suggest the limitations of Benjy's grasp of the world around him. But how does the reader arrive at this almost instinctive realization? There are some linguistic clues, and these are very suggestive, but by themselves they do not answer the question of how we give the passage the interpretation I have assigned to it.

Starling with the language: although it is deviant; it is not disintegrated in a haphazard fashion, but systematically patterned in certain areas of structure. Two observations are relevant here. First, random deviance or self-consistent deviance were options for Faulkner; they could be considered different models of mental deficiency. Second, certain types of structure, through repetition, are 'foregrounded' (a process well known to stylisticians): foregrounding implies perceptual salience for readers, a pointer to areas of significance.

Most striking is a consistent oddity in what linguists call transitivity: the linguistic structuring of actions and events. In this passage there are almost no transitive verbs; instead a preponderance of intransitives ('coming,' 'went,' 'hunting, 'ete.) and one transitive ('hit') used repeatedly without an object as if it were intransitive. It is implied that Benjy has little sense of actions and their effects on objects: a restricted notion of causation.

Second, Benjy has no names for certain concepts which are crucial to his understanding of what he is witnessing. In certain cases the word is supressed entirely: notably, the word 'golf'; in others he uses circumlocutions to designate objects for which he lacks a term: 'the curling flower spaces,' 'wherc the flag was,' the flower tree.' The implication of this is that he has command of only a part of his society's classification of objects.

Third, he uses pesonal pronouns in an odd way -look at the sequence 'them...they...They ...they...they...he...the other...' He uses these pronouns without identifying who he is referring to and with little variation in the pronoun forms themselves. It is suggested by this that Benjy does not appreciate what is needed if one wishes to specify to another person an object which one knows about but the other person does not. This would obviously be a severe communicative handicap.

Forth, there is a problem with Benjy's deictic terms: the words used to point to and orient objects and actions. There are plenty of these deictics in the passage: 
'Through...between...coming toward where...went along...etc. But these words do not add up to a consistent and comprehensible picture of the positions and movements of Benjy himself, his companion Luster, and the golfers whom they are watching. Try drawing diagrams of the sequence of positions and movements. Benjy is literally disoriented, with little sense of his location and of others' relationships with him within a context. The deictic inconsistency produces, for the reader, a sense of incoherence in the narrating, a feeling of being in the presence of a storyteller whose perceptions are disjointed.

In each of the above four paragraphs I have first noted a recurrent linguistic construction, and then added an interpretative comment. The question arises (or ought to!) of what is the authority for these comments. Let us be clear that there are no mimetic considerations involved, and no question of objective criteria for fidelity of representation: what reader could say 'I recognise this as an accurate rendering of the story-telling style of a person with such-and-such a cognitive disability"? and wouldn't this response anyway miss the point that language constructs fictions, rather than models reality? But it might be argued, on the 'fiction-constructing' premise, that what happens here is precisely that the specific language of this text somehow creates Benjy's consciousness ab initio. This kind of argument, common in literary criticism, has never seemed to me very plausible; since linguistic forms come to the writer already loaded with significances, it is unlikely that words and sentences could be used to create new meanings autonomously in a particular text. It is probable, then, that the significances here are conventional, but having said that it is necessary to define more precisely what is going on in the interaction between text, reader, and culture. At this stage of research, I cannot be absolutely exact, but can indicate something of the complexity of the processes.

Functional grammar maintains that linguistic constructions are selected according to the communicative purposes that they serve. It can be assumed that the total linguistic resources available to a speaker have been cumulatively formed by the communicative practices of the society into which s/he is born, and then by the practices in which s/he participates during socialization. On this theory, an explanation of my phrase 'loaded with significances' above would be that the linguistic units and structures available to an individual signify the associated functions: e. g. the word 'photosynthesis,' in addition to its dictionary meaning of a certain botanical life-process has the association of a scientific register of language; 'once upon a time' signifies narrative for children; and so on. If it were as simple as this, each individual would possess, in addition to his/her semantic and syntactic and phonological competence, a kind of 'pragmatic dictionary' in which the communicative and social significancies of forms were reliably stored. This would, of course, differ from individual to individual depending on their communicative roles within society, but with very substantial overlap.

The catch with this model is that linguistic forms may be pragmatically, as well as semantically, ambiguous. There is not an invariant relationship between form and function. So the linguistic critic, like the ordinary reader or hearer, cannot just recognise the linguistic structure and consulting his pragmatic competence, assign a significance to it. A more realistic view of linguistic 
interaction is that we process text as discourse, that is, as a unified whole of text and context -rather than as structure with function attached. We approach the text with a hypothesis about a relevant context, based on our previous experiences of relevant discourse, and of relevant contexts: this hypothesis helps us to point an interpretation, to assign significances, which are confirmed or disconfirmed or modified as the discourse proceeds. In the case of face-to-face interaction in conversation, feedback occurs to assist the refining of the hypothesis; with written texts, we are reliant on our existing familiarity with relevant modes of discourse and on our skill (developed in literary education and in other conscious studies of discourse, e. g. sociolinguistics) at bringing appropiate discourse models to bear. As critics know, the reader's realization of a literary text as discourse takes reading and re-reading, on the basis of the maximum possible previous experience of the canon of literature and of other relevant discourse; to assist this process and to affirm up our hypotheses, discussion with other experienced readers of literature is invaluable.

I am not an expert on Faulkner, and can only suggest the direction in which the analysis might go. 'The features noted can be traced in other texts which characterize various limitations of cognitive ability or of experience. For example, similar peculiarities of transitivity have been noted by Halliday in the language which depicts the thought-processes of William Golding's Neandertal Man Lok in his novel The Inheritors, and has interpreted them, as I have done here, as suggestions of a weak grasp of causation|9|. Circumlocutions like Benjy's 'the flower tree' are examples of a process called underlexicalization which is common in the characterization of naive, inexperienced people; cfr. my comments on Kingsley Amis's treatment of his provincial heroine Jenny Bunn in Take a Girl like You|10|. The use of personal pronouns without specifying their referents, according to the sociologist Basil Bernstein, is a sign of an excessive dependence on context characteristic of working-class speakers of restrictod code'; interestingly, this suggestion is not based on empirical evidence but on an example fabricated by a co-researcher; thus Bernstein is operating with an essentially fictional model[11].

The fact that the three texts I have referred to all come many years after the publication of The Sound and the Fury is not especially damaging: I am not, in this paper, discussing sources and influences, direct historical influence of one specific text upon another. I could readily find earlier instances of all four constructions with comparable cognitive significances (in older Gothic, naïve poetry, diaries and letters of poorly educated people, etc.), but the point is to show that there exist for the modern reader established modes of discourse for the characterization of naive consciousness and which guide her/him towards the interpretation which I have suggested. 'This is the only basis on which the contemporary critic can begin to read a text. Later stages of critical practice can, and perhaps ought to be, more strictly historical. Faulkner is building a specific model of idiocy, as, in the other sections of the novel, he is constituting other types of consciousness. The moral relationships between these points of view are of course the central concern of the fiction: Faulkner is juxtaposing modes of discourse to involve readers in a practice of evaluation. What literary, psychological and sociological discourses went to mould and articulate his 
models of deviant personalities is a question in historical sociolinguistics and pragmatics which I am not competent to answer without a great deal of research. But the research would be a kind of historical criticism of discourse and values. Critics may find it comforting that such research is compatible with the present theory of language -though of course not with previous formalist conceptions of linguisties stylisties.

Let me add a brief pedagogical and methodological conclusion. The theory of literature as language as I have articulated it is congruent with the elementary observations that students'critical performance, ability to 'read' in the sense of realising text as significant discourse, is very much dependent on how much and what they have read. Because reading and criticism depend on knowledge of discourse, not ability to dissect text structurally, it should not be expected that teaching formal linguistic analysis to beginning literature students will in itself produce any great advance in critical aptitude. However, linguistics of the kind indicated in this paper, with sociolinguistics, discourse analysis and pragmatics, in the context of a literature course of decent length -in our case three years- is very effective. In this type of course students mature gradually in their command of modes of literary discourse, simultaneously gaining a theoretical knowledge of language and its use, and an analytic method and terminology with which to describe the relationships between linguistic structures and their functions in 'literary' discourses. Finally, since discourse knowledge is formed for the individual in social structure, this approach is best taught and discussed in seminar groups rather than lectures and tutorials: thus experience of discourse can be shared.

Underlying this comments on linguistic criticism in literary education are my answers to some basic methodological -or meta-methodological-questions which were implicit in my opening discussion. These have to do with whether linguistic criticism is objective. The linguistic description of structures in texts is certainly objective, particularly at the levels of syntax and phonology (semantic description produces less agreement among linguists.) But it is clear that the assignment of functions or significances is not an objective process, because of the noted lack of co-variation of form and function. This does not mean that interpretation is a purely subjective, individual practice (a desperate and anarchic position into which those critics who stress the primacy of individual experience argue themselves.) Criticism is an intersubjective practice. The significances which an individual critic assigns are the product of social constitution; cultural meanings coded in the discourses in which the critic is competent. It is understandable, then, that critical interpretation is a matter of public discussion and debate; linguistic description, allowing clear descriptions of structures and a theory of social semiotic, is of fundamental importance in ensuring a clear grasp of the objective and intersubjective elements of texts under discussion. 
1. Roman Jakobson, "Concluding Statement: Linguistics and Poetics," in 'T. A. Sebeok, ed., Style in Language (Cambridge, Mass.: M.I.T. Press, 1960), p. 350.

2. David Lodge, Language of Fiction (London: Routledge and Kegan Paul, 1966), p. 57.

3. See Roger Fowler, "Linguistics and, and versus, Poetics," Journal of Literary Semantics, 8 (1979), 3-21; "Preliminaries to a Suciolinguistics Theory of Literary Discourse," Poetics, 8 (1979), $531-356$.

4. Lodge, op. eit., p. ix.

5. For relevant selections from Ilalliday's writings see G. R. Kress, ed., Halliday: System and Function in Language (I.ondon: (Oxford University Press, 1976); M. A. K. Halliday, Language as Social Semiotics (London: Edward Arnold, 1978).

6. For a recent introduction, set: G. N. Leech, Principles of Pragmatics (London: Longman, 1983).

7. See R. Fowler, Literature as Social Discourse (London: Batsford, 1981 ).

8. See II. II. Clark and E. V. Clark, Psychology and Language (New York: Harcourt, Brace Jovanovich, 1977), ch. 14.

9. M. A. K. Halliday, "linguistic Function and Literary Style: An Inquiry into the Language of William Golding's 'The Inheritors," in S. Chatman, ed., Literary Style: A Symposium (London and New York: Oxford University Press, 1971),pp.330-365.

10. R. Fowler, Linguistics and the Novel (I.ondon: Methuen, 2nd. ed., 1983), pp. 101-103.

11. B. Bernstein, Class, Codes and Control (London: Routledge and Kegan Paul, 1971 ), 1, 178-179. 